\title{
A Critical Review on Carbon Nanotubes
}

\section{Dr. Jayeshkumar Pitroda}

Assistant professor, Civil Engineering Dept., BVM Engineering College, Vallabh

Vidyanagar, Gujarat, India

\section{Bansri Jethwa}

Second Year Student, ME C E \& M., BVM

Engineering College, Vallabh Vidyanagar, Gujarat, India

\author{
Dr. S.K. Dave \\ Head Civil Engineering Dept. (GIA), \\ B \& B Institute of technology, Vallabh Vidyanagar, \\ Gujarat, India
}

\begin{abstract}
Nanoscience and nanotechnology provide gargantuan opportunities to engineers the properties of materials by working in atomic or molecular level. It has not only facilitated to overcome many limitations of conventional materials, but also extremely improved the mechanical, physical and chemical properties of the materials as well. To develop high performance, multifunctional, ideal (high strength, ductile, crack free, durable) construction material, carbon nanotubes (CNTs) show promising role to modify/enhance the characteristics of the conventional construction materials such as concrete and steel. In the paper, a brief on nanotechnology, carbon nanotubes, its application in various field and properties, possibilities and findings of different researchers on CNT is presented. It also covers comparison of carbon nano tubes with other nano materials.
\end{abstract}

Keywords: Nanotechnology, Carbon Nano Tube, Properties

\section{INTRODUCTION}

Nanotechnology is the use of very small pieces of material by themselves or their manipulation to create new large scale materials at nano scale material properties are altered from that of larger scales. The nano scale is the size of larger scales from approximately $1 \mathrm{~nm}$ to $100 \mathrm{~nm}$. Nanotechnology is facilitating technology that allows us to develop materials with improved properties.

With expanding population and an increase in construction and also due to limited resources and materials used, the demand for new materials in the construction industry increased. Try to find solution to improve quality, increase efficiency and reduce consumption of raw materials and energy, result in to use of new technologies in construction industry. Use of nanotechnology to improve the quality of building materials, including glass, plastic, wood, steel, construction alloys, ceramics, stone, concrete etc. In this paper, we explain the science of carbon nanotube particularly

\section{Area of Utilisation of Nano Technology}

Nanotechnology is widely used in construction material as: cement, steel, glasses, timber, coatings, water treatment, photovoltaic solar cell, nano sand, ceramics, metals, acoustic absorber, pipes etc.

\section{Advantages}

1. Smaller Inside

2. Low Cost per Computing

3. High Energy Efficient

4. Graphics Intensive

5. Free of energy leakage

6. Enable Multitasking 


\section{Disadvantages}

1. Environmental Risks

2. Privacy Risk

3. Not Portable

4. Possibility loss of Job in the traditional industry

\section{Carbon Nanotubes (CNTS)}

Carbon nanotubes (CNTs) are molecular carbon allotropes whose structure can be visualized as cylinders made up of rolled graphene layers. Two types of CNTs are differentiated depending on whether they consist of a single graphene wall (SWCNTs), or of multiple walls concentrically arranged (MWCNTs,) Shows in figure 1. The typical diameters of SWCNTs and MWCNTs range from 0.4 to $10 \mathrm{~nm}$ and from 4 to $100 \mathrm{~nm}$, respectively, while their lengths usually reach the micrometer range, although centimeters-long CNTs have been synthesized. Thus CNTs have very large aspect ratios (length to diameter ratio), typically higher than 1000 and reaching up to 2,500,000, which render their nanostructure quasi-one-dimensional (1D). Their ends can be open or capped by a half of a molecule of a fullerene, a carbon allotrope with a convex, approximately spherical shape that was first discovered in 1985. MWCNTs can have from tens to hundreds of walls, with typical adjacent walls separations of $0.34 \mathrm{~nm}$. Infinite forms of SWCNTs can exist, each one being uniquely characterized by its chiral angle, which defines the rolling direction of a hypothetical graphene layer, its diameter, and its length, along with the characterization of its terminations or caps, while the different possible combinations of walls a MWCNT can have given rise to infinitely more forms of CNTs. Although it is reported that CNTs were identified as early as 1952, it was not until the publication in 1991 of a paper on Nature by Iijima that they received worldwide attention and intense research began into their characterization, synthesis, and applications for a wide variety of fields. CNTs have exceptional mechanical, thermal, electrical, and optical properties which are being studied for promising applications as field emitters, composites materials for radio wave reflection and electrostatic discharge protection, bio molecular and chemical sensors, hydrogen storage media, fuel cell and catalyst supports, and composites with enhanced mechanical properties, among others. Several uses have been successfully commercialized.
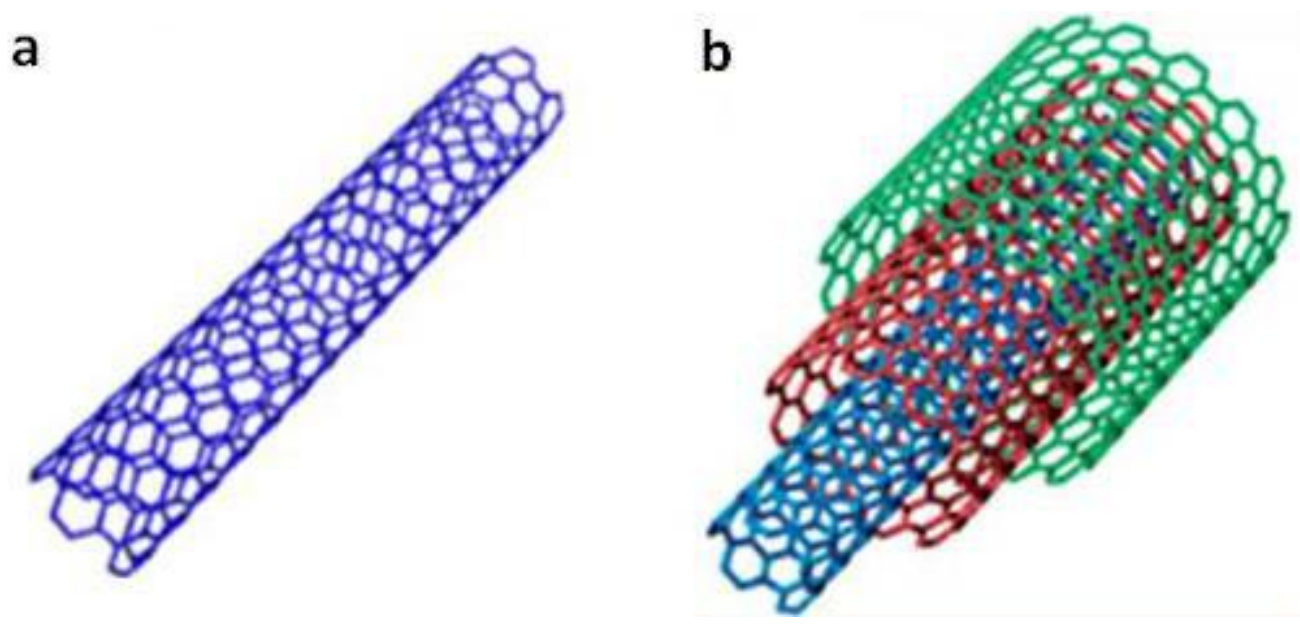

Figure1. Representation of a SWCNT (a) and a MWCNT (b)

\begin{tabular}{|l|l|}
\hline \multicolumn{1}{|c|}{ SWCNT } & \multicolumn{1}{c|}{ MWCNT } \\
\hline Single layer of graphene & Multiple layers of graphene \\
\hline Catalyst is required for synthesis & Can be produced without catalyst \\
\hline $\begin{array}{l}\text { Bulk synthesis is difficult as it requires proper } \\
\text { control over growth and atmospheric condition }\end{array}$ & Bulk synthesis is easy \\
\hline Purity is poor Purity is high & $\begin{array}{l}\text { A chance of defect is more during functionalization } \\
\text { A chance of defect is less but once occurred it is } \\
\text { difficult to improve }\end{array}$ \\
\hline Less accumulation in the body & It has very complex structure \\
\hline It can be easily twisted and is more pliable & It cannot be easily twisted \\
\hline Characterization and evaluation is easy & It has very complex structure \\
\hline
\end{tabular}




\section{Area of Utilization for Carbon Nanotubes (CNTs)}

1. Nano Balance

2. Magnetic Nanotubes

3. Nanotubes Reinforced Composites

4. Reinforcement armour \& Other Materials.

5. Reinforcement Polymer

6. Solar storage

7. Hydrogen storage

8. Thermal Protection

9. Space Elevator

\section{Advantages of Carbon Nanotubes (CNTs)}

1. Extremely small and lightweight making excellent replacement for metallic wires.

2. Resources required to produce them are plentiful and many can be made with only a small amount of material

3. Are resistant to temperature changes meaning function almost just as well as in extreme cold as they to in extreme heat.

4. Improve conductive mechanical properties of composites.

\section{Disadvantages of Carbon Nanotubes (CNTs)}

1. Despite all research researchers still don't understand how CNTs work.

2. Extremely small so are difficult to work with.

3. Currently the process relatively expansive to produce the nanotubes.

4. Would be expansive to implement this new technology in and replace the older technology in all the places that we could.

5. At the rate of technology has been becoming obsolete it may be a gamble to bet on this technology.

\section{Properties of Carbon Nanotubes (CNTs)}

\section{Mechanical Properties}

Carbon nanotubes are the strongest and stiffest materials yet discovered in terms of tensile strength and elastic modulus respectively. This strength results from the covalent $\mathrm{sp}^{2}$ bonds formed between the individual carbon atoms. Because of C-C bonds, CNTs are expected to be extremely strong along their axes and have a very large Young's modulus in their axial direction. The Young modulus value of a SWNT is estimated as high as 1Tpa to $1.8 \mathrm{Tpa}$. The high value of elastic modulus makes it suitable for the application as probe tips of scanning microscopy. The modulus of a SWNT depends on the diameter and chirality. However, in the case of MWNT, it correlates to the amount disorder in the sidewalls. For MWNTs, experiments have indicated that only the outer graphitic shell can support stress when the tubes are dispersed in an epoxy matrix 1,3 , and for single wall nanotube bundles (also known as ropes), it has been demonstrated that shearing effects due to the weak inter tube cohesion gives significantly reduced moduli compared to individual.

\section{Thermal Properties}

All nanotubes are expected to be very good thermal conductors along the tube, exhibiting a property known as "ballistic conduction, "but good insulators laterally to the tube axis. It is predicted that carbon nanotubes will be able to transmit up to $6000 \mathrm{~W} \cdot \mathrm{m}-1 \cdot \mathrm{K}-1$ at room temperature; compare this to copper, a metal well-known for its good thermal conductivity, which transmits $385 \mathrm{~W} \cdot \mathrm{m}-1 \cdot \mathrm{K}-1$. The temperature stability of carbon nanotubes is estimated to be up to $2800{ }^{\circ} \mathrm{C}$ in vacuum and about $750{ }^{\circ} \mathrm{C}$ in air. Thermal expansion of CNTs will be largely isotropic, which is different than conventional graphite fibers, which are strongly anisotropic. This may be beneficial for carbon-carbon composites. It is expected that low-defect CNTs will have very low coefficients of thermal expansion. 


\section{Chemical Properties}

The chemical reactivity of a CNT is, compared with a graphene sheet, enhanced as a direct result of the curvature of the CNT surface. This curvature causes the mixing of the $\pi$ and $\sigma$ orbital, which leads to hybridization between the orbitals. The degree of hybridization becomes larger as the diameter of a SWNT gets smaller. Hence, carbon nanotube reactivity is directly related to the $\pi$-orbital mismatch caused by an increased curvature. Therefore, a distinction must be made between the sidewall and the end caps of a nanotube. For the same reason, a smaller nanotube diameter results in increased reactivity. Covalent chemical modification of either sidewalls or end caps has shown to be possible. For example, the solubility of CNTs in different solvents can be controlled this way. However, covalent attachment of molecular species to fully sp2-bonded carbon atoms on the nanotube sidewalls proves to be difficult. Therefore, nanotubes can be considered as usually chemically inert.

\section{Limitation of Carbon Nanotubes (CNTs)}

1. Lack of solubility in most solvents compatible with the biological milieu (aqueous based).

2. The production of structurally and chemically reproducible batches of CNTs with identical characteristics.

3. Difficulty in maintaining high quality and minimal impurities.

Comparison of Carbon Nanotubes (CNTs) Properties

\begin{tabular}{|c|c|c|c|}
\hline Material & $\begin{array}{c}\text { Material Young's } \\
\text { modulus (GPa) }\end{array}$ & Tensile Strength $(\mathbf{G P a})$ & Density $\left(\mathbf{g} / \mathbf{c m}^{\mathbf{3}}\right)$ \\
\hline Single wall nanotube & 1054 & 150 & N/A \\
\hline Multi wall nanotube & 12001502.6 & 150 & 2.6 \\
\hline Steel & 208 & 0.4 & 7.8 \\
\hline Epoxy & 3.5 & 0.005 & 1.25 \\
\hline Wood & 16 & 0.008 & 0.6 \\
\hline
\end{tabular}

\section{Literature REVIEW}

The following are the previous research review based on carbon nanotubes (CNTs) in construction.

Valentin et al. (2004) The Carbon nanotubes are unique tubular structures of nanometer diameter and large length/diameter ratio. The amazing mechanical and electronic properties of the nanotubes stem in their quasi-one-dimensional (1D) structure and the graphite-like arrangement of the carbon atoms in the shells. Thus, the nanotubes Have High Young's modulus and tensile strength, which makes them preferable for composite materials with Improved mechanical properties.

Abdullah et al. (2007) on the basis of survey, cementitious and concrete materials are mainly used on a large scale and in huge quantities for roads, dams, bridges and building constructions, the mechanical behavior of these materials depended on a great extent on structural elements and phenomena which are effective on a micro and nanoscale. Nano fibrous cement based on materials can be monitored of regions of partial damages, localized changes in strains, stresses and temperatures of any joints and members. Nano fibrous cement based on materials can monitor regions of partial damages, localized changes in strains, stresses and temperatures of any joints and members.

Rajashree et al. (2009) discovered that cylindrical carbon molecules were having novel properties that were making them potentially useful in many applications in nanotechnology. They showed how the properties and characteristics of CNTs are still being researched heavily and scientists have barely Begun to tap the potential of these structures.

Saurav et al. (2012) Analysis stated that the application of nanotechnology in building materials for various civil engineering works. The use of nanotechnology controlled the matter at the atomic level; the properties of matter were seriously affected strength, durability and other properties of materials are dramatically affected under a scale of nano meter $\quad(10-9 \mathrm{~m})$. The use of nano technology makes concrete stronger, durable and more easily placed.

Sindhu et al. (2012) developed a conceptual framework on Recent technological advancements to manipulate materials in the nanometer scale had led to the intense research in nanotechnology. The findings indicated that the superior mechanical properties of Carbon Nanotubes (CNTs) were initiated to use this nanomaterial by construction industry. It was observed that the Young's modulus of 
nanotube of zigzag and armchair chirality had considerable effect for tubes of radius were less. Further, when the radius of CNT was greater, the Young's modulus did not vary much with the change in the tube radius and its chirality.

Jayshree et al (2013) conducted a review on the effect of multiwall carbon nanotubes (CNT) on strength characteristics and durability of concrete. They tested and conducted Sonication process by adding MWCNT with surfactants, in water with 36 Specimens in cement at 28 days of curing. After 28 days of curing the results showed an increase in compressive and splitting-tensile strengths of the samples with increasing MWCNT. As a result, Crack propagation was reduced and water absorption was decreased by $17 \%$ at 28 days curing. They noticed that by increasing the percentage of functionalized MWCNT to concrete, the water absorption was reduced to a greater extent which helped in improving the concrete to be more durable and water resistant.

Grigory et al. (2013) the analysis presented that results of the conducted researches on modifying traditional construction materials like cement concrete, anhydrite binders, silicate paint and fireretardant coating based on liquid glass. Modification was due to multi-walled carbon nanotubes dispersions uniformly distributed in binding matrices while preparing materials, which led to modification of the structure and the properties of materials and products.

Saptarshi et al. (2013) specified that nano science and nanotechnology provide enormous opportunities to engineers the properties of materials working in atomic or molecular level. It was not only facilitated to overcome many limitations of conventional materials, but also tremendously improved the mechanical, physical and chemical properties of the materials as well. To develop high performance, multifunctional, ideal (high strength, ductile, crack free, durable) construction material, carbon nanotubes (CNTs) show promising role to modify/enhance the characteristics of the conventional construction materials such as concrete and steel.

Siddique et al. (2014) conducted a survey which stated that the Carbon Nanotubes (CNTs) are primarily elemental carbon consisting of curved graphene layer which consists of a single layer of carbon atoms in a honeycomb structure that may contain varying amounts of metal impurities, depending on the method of manufacture. Effect of CNTs on properties such as compressive strength, tensile strength, modulus of elasticity, flexural strength, porosity, electrical conductivity and autogenous shrinkage are studied.

Jose et al. (2014) explained that Carbon nanotubes have extraordinary properties and thus they are considered as major candidates for diverse applications in nanotechnology. The main disadvantages they present are a lack of solubility and intricacies in handling. The analyzes states different research cases that have been carried out with cementitious materials to date and reviews the current state of the art and some future trends for these composites.

Kalpna et al. (2014) identified Carbon Nanotubes (CNTs) are allotropes of carbon with a nanostructure that can have a length-to-diameter ratio greater than 1,000,000. These cylindrical carbon molecules have novel properties that make them potentially useful in many applications in nanotechnology. Formally derived from the grapheme sheet they exhibit unusual mechanical properties such as high toughness and high elastic modality was hence derived that carbon nanotubes represent a material that offers great potential, bringing with it the possibility of breakthroughs in a new generation of devices, electric equipment and bio fields.

Ali et al. (2016) they examined, in the last decade due to the unique property of nanostructures materials that have demonstrated interest to research in the section of industry and research. in the meantime, the extraordinary properties that nanotubes of carbon have shown about the improvement of used materials in civil structures and enhancing capabilities of present sciences in the areas of structural and the result that from their behavior and performance in the durability and proficiency and other high potential among the new discovered material that is in the focus of researches. While research, we examined the Nano science technology in the field building structures, particularly the carbon Nano tubes and its types and will be examine several unique features this nanostructure in the building industry. They were having no acceptation that with the arrival of Nano science into the various fields of constructional researches which would be opened another world of science on the human.

\section{Conclusion}

Based on Literature Review the following conclusions are drawn: 
1. Effect of CNTs on properties such as compressive strength, tensile strength, modulus of elasticity, flexural strength, porosity, electrical conductivity and autogenous shrinkage are studied that indicated that the superior mechanical properties of Carbon Nanotubes (CNTs) were initiated to use this nanomaterial by construction industry.

2. In fact, carbon nanotubes are insoluble in all organic solvents and aqueous solutions, and thus they require to be dispersed by using surfactants or chemical agents, in addition to vigorous agitation by sonication. Carbon nanotubes have been widely used with polymers in composite materials in order to improve their mechanical and electromagnetic properties.

3. It can be comprehensively reviewed that the feasibility of developing new cements with a maximum carbon nanotube content of $0.5 \%$ in order to provide large increases in flexural strength and in compressive strength, along with a reduction in porosity.

4. It can be analyzed from different research cases that have been carried out with cementitious materials to date and review the current state of the art and some future trends for these composites.

5. They noticed that by increasing the percentage of functionalized MWCNT to concrete, the water absorption was reduced to a greater extent which helped in improving the concrete to be more durable and water resistant.

6. To develop high performance, multifunctional, ideal (high strength, ductile, crack free, durable) construction material, carbon nanotubes (CNTs) show promising role to modify/enhance the characteristics of the conventional construction materials such as concrete and steel.

7. Their unique surface area, stiffness, strength and resilience have led to much excitement in the field of pharmacy. Nanotubes are categorized as single-walled nanotubes and multiple walled nanotubes. Techniques have been developed to produce nanotubes in sizeable quantities, including arc discharge, laser ablation, chemical vapor deposition, and saline solution method and flame synthesis Method.

8. Without doubt, carbon nanotubes represent a material that offers great potential, bringing with it the possibility of breakthroughs in a new generation of devices, electric equipment and bio fields. Thus CNT can also be included for further research in construction industry.

9. Finally, few pre-proof of concepts are mentioned where CNTs can play the pivotal role to redefine the scope and ability of civil engineering, in general engineering, in particular. High performance, multifunctional, ideal (high strength, ductile, crack free, durable) construction material of the carbon nanotubes (CNTs) show promising role to modify/enhance the characteristics of the conventional construction materials such as concrete and steel.

\section{ACKNOWLEDGMENT}

The Authors thankfully acknowledge Dr. C. L. Patel, Chairman, Charutar Vidya Mandal, Er.V.M.Patel, Hon. Jt. Secretary, Charutar Vidya Mandal, Dr. Indrajit N. Patel, Incharge Principal, BVM Engineering College, Dr. L. B. Zala, Professor and Head, Civil Engineering Department, BVM Engineering College, Prof. J. J. Bhavsar, Associate Professor and P.G. Coordinator (Construction Engineering and Management), B.V.M. Engineering College, India for their motivations, support and cooperation to carry out this research.

\section{REFERENCES}

[1] Dr.T.Ch.Madhavi, Pavithra.P, Sushmita Baban Singh, S.B.Vamsi Raj, Surajit Paul, "Effect of Multiwalled Carbon Nanotubes on Mechanical Properties of Concrete" Volume: 2, Issue: 6, June 2013, ISSN No 2277 - 8179

[2] Sindu B S, Saptarshi Sasmal, Smitha Gopinath and Nagesh R Iyer, "Carbon Nanotubes Structure, Properties and Modelling Aspects", Proc. of Int. Conf. on Structural and Civil Engineering 2012, DOI: 03.CES.2012.2.510

[3] 11th International Conference on "Modern Building Materials, Structures and Techniques," MBMST 2013_Modification of Construction Materials with Multi-Walled Carbon Nanotubes

[4] Abdullah Keyvani, "Huge opportunities for industry of Nano fibrous concrete technology", International Journal of Nanoscience and Nanotechnology 21 Apr 2007

[5] Saurav "Application of Nanotechnology in Building Materials", International Journal of Engineering Research and Applications (IJERA), ISSN: 2248- 9622, www.ijera.com, Vol. 2, Issue 5, September- October 2012 
[6] Rafat Siddique, Ankur Mehta, "Effect of carbon nanotubes on properties of cement mortars" Construction and Building Materials 50 (2014) 116-129

[7] Jose Luis Fraga, Jose María del Campo, and Juan Ángel García, "Carbon nanotube in cement composites in the construction industry 1952-2014. A state of art review". 2nd International Conference on Emerging Trends in Engineering and Technology (ICETET'2014), May 30-31, 2014 London (UK)

[8] Kazempour, Ali., "The impact of Nanotechnology in reinforced structures the structure of Concrete and steel", Journal of Current Research in Science, page:422-430

[9] Rajashree Hirlekar, Manohar Yamagar, Harshal Garse, Mohit Vij, Vilasrao Kadam, "Carbon Nanotubes and Its Applications: A Review", Vol.2, Issue 4, October- December 2009, Asian Journal of Pharmaceutical and Clinical Research, ISSN 0974-2441

[10] Kalpna Varshney, "Carbon Nanotubes: A Review on Synthesis, Properties and Applications", International Journal of Engineering Research and General Science, Volume 2, Issue 4, JuneJuly, 2014, ISSN 2091-2730

[11] Valentin N Popov, "Carbon nanotubes: properties and application". Materials Science and Engineering R 43 (2004) 61-102

\section{AUTHORS' BIOGRAPHY}

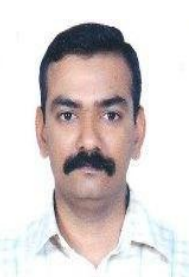

Dr. Jayeshkumar R. Pitroda, received his Bachelor of Engineering degree in Civil Engineering from the Birla Vishvakarma Mahavidyalaya, Sardar Patel University in 2000. In 2009 he received his Master's Degree in Construction Engineering and Management from Birla Vishvakarma Mahavidyalaya, Sardar Patel University. In 2015 he received his Doctor of Philosophy (Ph.D.) Degree in Civil Engineering from Sardar Patel University. He joined Birla Vishvakarma Mahavidyalaya Engineering College as a faculty in 2009, where he is Assistant Professor of Civil Engineering Department with a total experience of 16 years in the field of Research, Designing and education. He is guiding M.E. (Construction Engineering \& Management) Thesis work in the field of Civil/Construction Engineering. He has published many papers in National / International Conferences and International Journals. He has published seven Research Books in the field of Civil Engineering, Rural Road Construction, National Highways Construction, Utilization of Industrial Waste, Fly Ash Bricks, Construction Engineering and Management, Eco-friendly Construction.

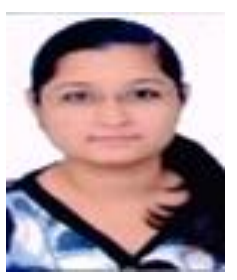

Bansri Jethwa, was born in 1992 in Vallabh Vidhyanagar. She received her Bachelor of Engineering degree in Civil Engineering from the Birla Vishvakarma Mahavidyalaya, Gujarat Technological University., in 2014. At present, She is 2nd year student of Master's Degree in Construction Engineering \& Management from Birla Vishvakarma Mahavidyalaya, an autonomus institute.

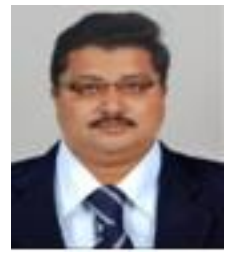

Dr. Sanjaykumar Kanubhai Dave, received his Bachelor of Engineering degree in Civil Engineering from BVM Engineering College (Sardar Patel University, Vallabh Vidyanagar) in 1989 and M.E (Civil) in Water Resources Management in 1992 from L. D. College of Engineering (Gujarat University, Ahmedabad) with Distinction. He was awarded Ph.D degree in Civil Engineering in January 2012 from L. D. College of Engineering (Gujarat University, Ahmedabad). At present he is working as Head of Civil Engineering Department (GIA) and I/c Head of the Civil Engineering Department (SF) at B \& B Institute of Technology, Vallabh Vidyanagar. He has field experience of 5.5 years and teaching experience of about 20 years. He is having teaching experience of almost all subjects of Applied Mechanics and Civil Engineering. He has published / presented many papers in National / International Journals and conferences. He is awarded Best Teacher award for Gujarat state by Indian Society of Technical Education, New Delhi at 43rd National annual Convention. He is awarded Gaurav Purshkar award from Charutar Vidya Mandal, V. V. Nagar in 2014. He has also got Best Research Paper Award in 19th ISTE Annual Convention held at L. D. College of Engineering, Ahmedabad. He also received best poster award of 1 st international conference of ISTE Gujarat section at pattaya, Bankog. 